Article

\title{
Price Elasticity of Heat Demand in South Korean Manufacturing Sector: An Empirical Investigation
}

\author{
Hyo-Jin Kim, Jae-Sung Paek and Seung-Hoon Yoo * \\ Department of Energy Policy, Graduate School of Energy \& Environment, Seoul National University of Science \& \\ Technology, 232 Gongreung-Ro, Nowon-Gu, Seoul 01811, Korea; hjinkim@seoultech.ac.kr (H.-J.K.); \\ jsbaekc@seoultech.ac.kr (J.-S.P.) \\ * Correspondence: shyoo@seoultech.ac.kr; Tel.: +82-2-970-6802
}

Received: 30 August 2019; Accepted: 29 October 2019; Published: 4 November 2019

\begin{abstract}
Heat is a crucial input supplied in the form of steam or hot water to industrial production of South Korea. Estimating the demand function for heat in the manufacturing sector is all the more important a task in terms of policy because heat consumption in the manufacturing sector is increasing because using heat directly as a fuel can reduce the air pollutants emissions and save energy when compared with using electricity, which is secondary energy. Thus, this article tries to estimate the demand function for industrial heat in the manufacturing sector of South Korea using cross-sectional data for analyzing the influence of manufacturing firms' characteristics. To this end, 257 observations collected from a nationwide survey of manufacturing firms in 2017 are used and analyzed. As a robust approach, the least absolute deviations estimation method is applied to obtain the demand function. The results show that the price elasticity and sales amount elasticity of the industrial heat demand are estimated to be -0.8476 and 1.0144 , respectively, which are statistically significant at the $1 \%$ level. Furthermore, the economic benefits of industrial heat consumption are computed to be 1.59 times as great as the price of heat. The results of this study can be utilized in policy planning, making, and evaluation.
\end{abstract}

Keywords: industrial heat; demand function; price elasticity; least absolute deviations; economic benefits

\section{Introduction}

The most basic way for manufacturing plants to receive the heat needed for the production process is for each manufacturing firm to install individual boilers to produce the required heat. That is, individual manufacturers are both consumers and suppliers of the industrial heat. Factories that need industrial heat also need electricity. Each manufacturing firm produces heat directly and purchases electricity generated from the power plants through the power sales operator. This method of producing heat and electricity separately consumes more energy than cogeneration, which produces both heat and electricity. In particular, South Korea depends on imports from abroad for about 95 percent of its energy consumed, making its economic structure highly vulnerable to fluctuations in international energy prices and making energy imports an important factor aggravating the trade balance.

In this situation, cogeneration or combined heat and power (CHP) is a very efficient method of producing industrial heat [1-3]. It uses less energy to utilize heat from the process of cogeneration, not individual boilers, and it also emits less greenhouse gases $[4,5]$. Therefore, the South Korean government has fostered industrial complex CHP businesses that provide heat to factories that are located in the industrial complex and need industrial heat and sell electricity to a power supply company. In the case of individual boilers installed by each manufacturer, if a failure occurs, the heat supply may be interrupted, resulting in production interruption, among other things. However, the industrial complex CHP business can supply industrial heat reliably because it is also constructing large-scale 
boilers for emergency use, as well as the CHP plant. In addition, because the cost of producing heat with CHP is lower than the cost of producing heat with individual boilers, the industrial complex CHP business is contributing to strengthening industrial competitiveness. For this reason, the government also approves the industrial complex CHP business while developing industrial parks. In other words, supplying industrial heat reliably and cheaply through CHP is an industrial policy and, at the same time, is an axis of energy policy. The government and the industrial complex CHP businesses need information about demand function, including price elasticity of demand, for industrial heat for policy making and evaluation, as well as business activities.

Heat is an essential input to industrial production, such as labor and capital. The activity of producing goods or services through the input of heat results in an increase in sales or value added [6]. As of 2017, industrial heat of 77,852,593 Gcal in total was supplied in the form of steam or hot water to the manufacturing sector. The sources of industrial heat were CHP $(63,745,029 \mathrm{Gcal}, 81.9 \%)$; boilers (6,636,278 Gcal, 8.5\%); solar heat, heat pump, and fuel cell (3,535,518 Gcal, 4.5\%); and waste heat from incineration, sewage water, and power plants (3,935,768 Gcal, 5.1\%) [7]. Increased value added by the industrial sector through the stable supply of industrial heat has played an important role in South Korea. This is because using heat directly as a fuel can reduce air pollutant emissions and save energy compared with using electricity, which is secondary energy [8-10].

Thus, there is a growing number of companies that want to receive heat stably. If heat is not properly supplied to the manufacturing sector, the country will suffer a negative impact on growth, beyond just inconvenience [11]. For example, in case the heat supply is suddenly interrupted because of an unexpected surge in demand for heat in the manufacturing sector, the manufacturing sector can suffer massive damage. The most basic information in analyzing the heat demand pattern of manufacturing will be the industrial heat demand function.

Therefore, it is necessary to estimate the industrial heat demand function by identifying the determinants affecting the heat demand for industrial use. The heat demand function has various uses. First, it is possible to induce information about the price elasticity of heat demand from the heat demand function [12]. This can be useful for ex-ante evaluation of the impact of pricing policy on the demand-side management of heat [13-15]. Second, the sales elasticity of heat demand can be derived from the heat demand function. This can be used to develop heat producing and transportation facilities plans, taking into account the impact of expected future changes in sales or industrial size on heat demand. Third, using the price elasticity of demand derived from the heat demand function, the economic value or benefits of heat consumption can be estimated $[13,16]$. Information on the economic value or economic benefits of heat consumption is essential in the economic feasibility analysis of new heat supply projects. Fourth, the heat demand function can be used to identify various factors affecting heat demand and the extent of their impact, which are then utilized to predict future heat demand.

In short, it is necessary to estimate the price elasticity of demand and the sales elasticity of demand after estimating the heat demand function for industrial use. This article seeks to estimate the heat demand function for industrial use in the manufacturing sector. There have been many studies about the demand for energy [17-27]. To the best of the authors' knowledge, however, there is no research that dealt with the demand function of industrial heat in the literature. Although most of the studies are based on panel data [17-21] and time series data [12,22,23], some used cross-sectional data [16,24,25]. Cross-sectional data are often unable to include data on confounding factors-other variables that affect the relationship between the putative cause and effect. For example, data only on present industrial electricity price and industrial electricity demand would not allow the role of past industrial electricity use, or of other causes, to be explored. On the other hand, panel data enable one to analyze many important economic questions that cannot be addressed using cross-sectional or time-series data sets. However, to obtain panel data requires considerable time and cost than to obtain cross-sectional data.

Unlike other studies, this study aims to estimate the demand for industrial heat using cross-sectional data to analyze the influence of manufacturing firms' characteristics. To this end, 257 available observations were gathered from a heat consumption survey, which was conducted on manufacturing 
firms nationwide in 2017. The authors expect the implications of this paper to be useful, as it is the first attempt to estimate the heat demand function for industrial use using micro data obtained through a survey of manufacturers.

The subsequent composition of this paper is as follows. Section 2 looks at models and methodologies related to estimating the industrial demand function for industrial use and the data used. In particular, the least absolute deviations (LAD) estimation method given in Koenker and Bassett [26] is used as a robust approach rather than the ordinary least squares estimation method for estimating the demand function. Section 3 presents and discusses the analysis results. It will elicit some elasticity information and explore the factors that affect industrial heat demand. The last section outlines the conclusions.

\section{Model and Data}

\subsection{Model}

In order to estimate the demand function, both dependent and independent variables of the demand function must first be defined. The dependent variable, of course, is the annual industrial heat demand. According to microeconomic theory, price and income should be included as independent variables of the demand function. The law of demand implies that the coefficient for the price variable must be negative. In other words, a higher price of a good or service induces less demand for the good or service, and a lower price of a good or service causes more demand for the good or service. If the good or service of concern is a normal good or service, the coefficient for the income variable in the demand function is positive, and if the good or service of concern is an inferior good or service, the coefficient for the income variable in the demand function is negative. However, the income variable is not well defined in this study, which estimates the heat demand function for industrial use, as the data collected from a survey of manufacturing firms are used. Therefore, the sales amount will instead be used as a proxy variable for income. Several other factors that may affect demand will be identified and considered as additional independent variables.

The next step in estimating the demand function is to determine the form of the demand function. Economic theory provides no clues as to the form of a demand function. However, the usual practice in the literature concerning estimating demand functions indicates that the natural logarithms of all continuous variables are used. This makes it easy to estimate the elasticity of demand because the coefficient for each variable is interpreted as elasticity. In addition, the natural logarithm of an economic time-series that is defined only on the positive range of real numbers is defined on the whole range of real numbers, making it easier to deal with the demand function. The natural logarithm is not used for dummy variables.

Let $r$ denote the $r$ th firm for $r=1, \ldots, R, Q_{r}$ be the annual industrial heat demand $(\mathrm{kWh})$ of the $r$ th firm, $k$ be the number of independent variables, $Z_{r}$ be the $k \times 1$ column vector of factors affecting the heat demand of the $r$ th firm, $\delta$ the $k \times 1$ column vector of coefficients corresponding to $Z_{r}$, and $\mu_{r}$ be the disturbance term. The industrial heat demand function estimated in this study has the following form:

$$
Q_{r}=Z_{r}^{\prime} \delta+\mu_{r}
$$

Usually, the least squares (LS) estimation method is applied to obtain the estimate for $\delta$ in Equation (1). However, the LS estimation method has a critical problem in that the LS estimator is not robust to the possible existence of outliers. In such a case, the LAD estimation method, which is known to be a robust approach, can be used as an alternative to the LS estimation method. Whereas the LS estimation method has the characteristic of obtaining mean values that are vulnerable to the influence of an outlier, the LAD estimation method has the characteristic of obtaining median values that are not affected by the outlier. If we apply the LS estimation method, it is easy to obtain estimates using differentiation. On the other hand, applying the LAD estimation method cannot use differentiation because the objective function has absolute values, and somewhat complex simplex algorithms should 
be employed. This is not a problem because it is not difficult to employ the simplex algorithm owing to the development of the personal computers that researchers use.

Let $\delta_{L A D}$ be the LAD estimator. From Bassett and Koenker's [27] paper, $\delta_{L A D}$ can be obtained as follows:

$$
\delta_{L A D}=\underbrace{\operatorname{argmin}}_{\delta} \sum_{r=1}^{R}\left|Q_{r}-Z_{r}^{\prime} \delta\right| \cdot \delta_{L A D}=\underbrace{\operatorname{argmin}}_{\delta} \sum_{r=1}^{R}\left|Q_{r}-Z_{r}^{\prime} \delta\right| .
$$

\subsection{Data Collection Process}

Information about both the amount and the price of industrial heat use is essential for estimating the industrial heat demand function. However, because no such data were available, it was necessary to perform a survey of industrial heat consumers to obtain the data. Therefore, we secured a sufficient budget for implementing the survey and commissioned a professional survey company to conduct the survey. Survey experts from the company visited the industrial heat consumers, asked the employees who were able to provide the information to bring the industrial heat bill, and collected the necessary information.

The survey period was about two months from the beginning of September to the end of October 2018, and the survey was conducted on about 1000 manufacturing firms in the country. Some firms failed to respond to some important items, which eventually caused some observations to be excluded from the dataset to be analyzed. Finally, 257 available observations were obtained. The variables used for estimating the demand function are described in Table 1.

Table 1. Description of variables in the model.

\begin{tabular}{|c|c|c|c|c|c|c|c|c|}
\hline Variables & Definitions & Mean & $\begin{array}{l}\text { Standard } \\
\text { Deviation }\end{array}$ & Median & $\begin{array}{c}\text { 1st } \\
\text { Quartile }\end{array}$ & $\begin{array}{c}\text { 3rd } \\
\text { Quartile }\end{array}$ & Skewness & Kurtosis \\
\hline$Q$ & $\begin{array}{l}\text { Annual demand for industrial heat during } \\
2017 \text { (unit: tonne) }\end{array}$ & 17,092 & 221,768 & 1215 & 901.50 & 1353 & 15.95 & 255.11 \\
\hline$P$ & $\begin{array}{l}\text { Average price of industrial heat during } 2017 \\
\text { (unit: Korean won per tonne) }\end{array}$ & 39,727 & 2546 & 0.04 & 0.04 & 0.04 & -1.57 & 10.52 \\
\hline$S$ & $\begin{array}{l}\text { Sales amount during } 2017 \\
\text { (unit: million Korean won) }\end{array}$ & 94,722 & $1,119,559$ & 13,000 & 9768 & 15,000 & 15.82 & 252.25 \\
\hline$L$ & $\begin{array}{l}\text { Average price of labor during } 2017 \\
\quad \text { (unit: million Korean won) }\end{array}$ & 33.99 & 8.70 & 33.00 & 29.00 & 38.00 & 3.78 & 26.49 \\
\hline K & $\begin{array}{l}\text { Average price of capital during } 2017 \\
\quad \text { (unit: billion Korean won) }\end{array}$ & 0.54 & 0.29 & 0.51 & 0.51 & 0.52 & 5.62 & 43.38 \\
\hline$M$ & $\begin{array}{l}\text { Average price of intermediate goods during } \\
2017 \text { (unit: billion Korean won) }\end{array}$ & 0.79 & 0.08 & 0.81 & 0.78 & 0.81 & -4.99 & 31.35 \\
\hline E & $\begin{array}{l}\text { Average price of industrial electricity during } \\
2017 \text { (unit: Korean won per kWh) }\end{array}$ & 109.23 & 13.56 & 106.35 & 105.23 & 107.84 & 3.39 & 20.28 \\
\hline$S M$ & $\begin{array}{l}\text { Classification of firms }(1=\text { small and medium } \\
\text { sized enterprise; } 0=\text { large enterprises })\end{array}$ & 0.96 & 0.19 & 1 & 1 & 1 & -4.80 & 21.17 \\
\hline
\end{tabular}

The dependent variable, $Q$, is defined as the annual demand for industrial heat during 2017 (unit: tonne). In South Korea, a total of 37 industrial heat providers produce heat and power through combined heat power (CHP) co-generation, sell produced electricity to Korea Electric Power Corporation, and supply heat to manufacturing firms. Industrial heat is supplied to the consumers at the same temperature and at the same price in the form of hot water between $100^{\circ} \mathrm{C}$ and $120^{\circ} \mathrm{C}$. Heat is originally measured in energy units such as calories. However, industrial heat suppliers charge industrial heat with a mass unit of ton instead of calories. In addition, neither the heat providers nor the consumers aggregate how much heat they have used. Therefore, during the survey of industrial heat consumers, the data on the amount and price of industrial heat use were collected using the unit of ton. This is why heat use was measured in terms of mass, not energy units, in this study.

A total of eleven independent variables are used, apart from a constant term. The two essential independent variables in estimating the demand function are price and income. As a price variable, the average price, defined as the total heat charge divided by the amount of heat used, is adopted in this study. As explained above, the sales amount is used as a proxy for the income variable. 
The two-part tariff system consists of two price variables. The first price variable is fixed charges and levied on all consumers with almost the same level irrespective of the amount of industrial heat consumed. Industrial heat suppliers recoup the expenses invested in the heat supply network through the fixed charges. The second price variable is the rate per unit of industrial heat. The variable charges are proportional to the amount of industrial heat use. That is, the variable charges are calculated by multiplying the amount of industrial heat use by the unit price. Therefore, the total industrial heat charge paid by an industrial heat consumer amounts to the sum of the fixed and variable charges. In the literature, the average price has almost always been used as a price variable for two reasons when estimating the demand function for goods adopting the two-part tariff system, such as the industrial heat in South Korea (e.g., the works of [28,29]).

First, estimating demand functions using the first price variable or the second price variable creates the problem of identification. Because the fixed charges are the same for all consumers, estimating the demand functions including the fixed charges as a price variable creates an econometric problem that the coefficient for the first price variable cannot be estimated. Similarly, the unit price is also constant for all consumers, which results in the same problem of identification. In summary, the demand function itself cannot be estimated when using either the first price variable or the second price variable. According to microeconomics, a number of consumers must consume different amounts of goods at different prices to obtain a demand function for the goods. Second, although there are two prices in the two-part tariff system, it does not seem that consumers respond to each of the two prices. In particular, it is unreasonable to say that the demand responds to fixed charges, given the nature of fixed charges that are constant, regardless of the amount of use. The unit price is also constant for all consumers and thus cannot explain the fact that each consumer uses a different amount of industrial heat. It is not persuasive to say that consumers respond to a constant unit price to determine different consumption levels. Therefore, it is reasonable to assume that consumers determine the demand for industrial heat in response to the average price defined as total expenditure on the industrial heat divided by the total consumption for the industrial heat.

Because industrial heat is used as an intermediate good for producing final goods rather than as a final good, the demand for industrial heat is a derived demand. That is, according to the neoclassical theory of production, the heat demand function for industrial use is derived through the first-order condition under the objective function of a firm's profit maximization or cost minimization. In other words, solving the problem of profit maximization and the problem of cost polarization results in an inverse demand function and demand function for industrial heat, respectively. That is, the industrial heat demand will depend on the heat price, the prices of the other inputs, and the scale of production. Therefore, this study basically reflects the heat price, capital price, labor price, intermediate goods price, sales, and electricity price as independent variables of the demand function, and includes several additional characteristic variables of the firm that may affect heat demand. In theory, the scale of production should be used as an independent variable, but the amount of sales that can be expressed in a uniform monetary unit is utilized because the types and units of products vary from firm to firm.

In this regard, labor price, $L$, defined as the annual average wage divided by average number of employees; capital price, $K$, explained as value of fixed assets at the end of the year divided by sales amount during 2017; intermediate goods price, $M$, the value of intermediate goods divided by sales amount during 2017; and electricity price, $E$, described as the total electricity charge divided by total amount of electricity use, are considered as independent variables. The dummy variable associated with the size of firms is reflected in the estimation of the demand function for heat, as the overall heat demand may vary depending on the size of firms. SM indicates the dummy variable for the classification of firms ( $1=$ small and medium sized enterprises; $0=$ large enterprises $)$. 


\section{Estimation Results of the Demand Function}

\subsection{Estimation Results of the Demand Function}

Omitting $r$ for brevity, the estimable econometric form of the demand function for industrial heat can be expressed as follows:

$$
\ln Q=\delta_{0}+\delta_{1} \ln P+\delta_{2} \ln S+\delta_{3} \ln L+\delta_{3} \ln K+\delta_{4} \ln M+\delta_{5} E+\delta_{6} S M+\mu
$$

The method for estimating the demand function given in Equation (3) should be determined. The most widely applied estimation method is the least squares (LS) estimation, which finds the mean. For this reason, the LS estimation method is called mean regression. The median and mean values of the annual demand for industrial heat during 2017 given in Table 1 are 1215 and 17,092, respectively. The difference between the two is quite large. In particular, the 1st quartile and the 3rd quartile are 901.50 and 1353, respectively. The mean value is about twelve times larger than the 3rd quartile. This implies that outliers exist in our data for the demand. The skewness is 15.95 , which is much greater than zero. There exists the long-tail in the positive direction. The kurtosis is 255.11, which is much bigger than three, showing that the long-tail of the distribution is quite thick. Thus, the application of the LS method in estimating the demand function may result in poor robustness. In this study, the LAD estimation method, known as robust estimation method, is applied. The LAD estimation method is called median regression, which indicates that it finds the median, a robust location value, unlike the LS estimation, which seeks the mean.

The results of applying the LS and LAD estimation methods are presented in Table 2. Interestingly, the results from the LAD estimation show that the estimated coefficients for seven variables are statistically significant at the $5 \%$ level. On the other hand, when looking at the LS estimation results, only the estimated coefficients for six variables are statistically significant at the $5 \%$ level. Of course, it is unclear whether the existence of outliers and/or the long-tail is the cause of these estimation results or not. However, from the viewpoint of the statistical significance of the estimated coefficients, it seems clear that the LAD estimation outperforms the LS estimation. Therefore, in this study, we will accept the LAD estimates rather than the LS estimates and make further explanations based on the LAD estimates.

Table 2. Estimation results of the demand function for industrial heat.

\begin{tabular}{|c|c|c|c|c|}
\hline \multirow{2}{*}{ Variables $^{\text {a }}$} & \multicolumn{2}{|c|}{ Least Squares Estimation } & \multicolumn{2}{|c|}{ Least Absolute Deviations Estimation } \\
\hline & $\begin{array}{l}\text { Coefficient } \\
\text { Estimates }\end{array}$ & $t$-Values & $\begin{array}{l}\text { Coefficient } \\
\text { Estimates }\end{array}$ & $t$-Values \\
\hline Constant & -12.0770 & $-3.58^{\#}$ & -8.3634 & $-7.01^{\#}$ \\
\hline $\operatorname{Ln} P$ & -3.0196 & $-4.09^{\#}$ & -0.8476 & $-3.25^{\#}$ \\
\hline $\ln S$ & 0.9914 & $9.73^{\#}$ & 1.0144 & $28.19^{\#}$ \\
\hline $\operatorname{Ln} L$ & -0.2642 & $-1.02^{\#}$ & -0.0218 & -0.24 \\
\hline $\operatorname{Ln} K$ & 0.2492 & 2.03 & 0.4198 & $9.67^{\#}$ \\
\hline $\operatorname{Ln} M$ & -1.9139 & $-6.38^{\#}$ & -1.6266 & $-15.37^{\#}$ \\
\hline $\operatorname{Ln} E$ & -0.3134 & -0.70 & 0.3453 & $2.18^{\#}$ \\
\hline$S M$ & 2.3005 & $5.11^{\#}$ & 1.5033 & $9.46^{\#}$ \\
\hline Sample size & \multicolumn{2}{|c|}{257} & \multicolumn{2}{|c|}{257} \\
\hline$R^{2}$ & \multicolumn{2}{|c|}{0.469} & \multicolumn{2}{|c|}{0.428} \\
\hline Wald statistic ( $p$-value) ${ }^{\mathrm{b}}$ & \multicolumn{2}{|c|}{$24,235(0.000)$} & \multicolumn{2}{|c|}{$189,141(0.000)$} \\
\hline
\end{tabular}

Notes: ${ }^{\mathrm{a}}$ The variables are described in Table $1 .{ }^{\mathrm{b}}$ The null hypothesis is that all the parameters are jointly zero. The dependent variable is the natural logarithm of heat demand. \# denotes that the estimated coefficient is statistically meaningful at the $5 \%$ level.

We apply the Wald test to conduct a specification test of the model. The Wald statistic is distributed as chi-squared with seven degrees of freedom under the null hypothesis that all the estimated coefficients are zero. The Wald statistic is computed as 189,141 , which is large enough to reject the null hypothesis 
at the $1 \%$ level, as the critical value at the $1 \%$ level is about 26.2 . The coefficient of determination $\left(R^{2}\right)$ is calculated to be 0.428 , which means that the model explains $42.8 \%$ of the variation of the dependent variable. Considering that the data used in this study are cross-sectional, the value is not low.

The coefficient for the price term is estimated to be -0.8476 , which is the price elasticity of heat demand. Its sign and value imply that the law of demand applies well to the industrial demand for heat and the demand is inelastic to a change in price for heat. In other words, a $1 \%$ increase (decrease) in heat price reduces (increases) heat demand by $0.8476 \%$. The sales amount elasticity of heat demand is computed to be 1.0144 . The input of heat positively contributes to increased sales by manufacturing firms. If the sales amount increases (decreases) by $1 \%$, heat demand increases (decreases) by $1.0144 \%$. The coefficient for the intermediate goods' price input is negative, which means that with a rise in intermediate goods' price, heat demand will decrease. On the other hand, the coefficients for capital price and electricity price inputs are positive. The sign of the estimated coefficients for capital price and electricity price indicates that if capital price and electricity price rise, the heat demand will also increase. The estimated coefficient for the SM term is statistically significant at a significant level of $1 \%$. If other conditions are the same, firms that belong to the small and medium sized enterprises consume more industrial heat than the large enterprises do.

We have tried to consider the nature of heterogeneous data in two ways. First, we have included seven independent variables, constant term, S, L, K, M, E, and SM, except for the price variable, in the demand function. They can reflect individual heterogeneity. Second, we have applied a robust approach rather a conventional least squares approach to estimate the demand function. Although the latter may be vulnerable to any existence of outliers, the former is not. Even if the data are heterogeneous, the former is known to provide robust estimates.

\subsection{Implications of the Results}

Regarding the implications of the results, there are some points to be addressed. The first concerns the magnitude of the price and sales amount elasticity. As explained above, the price and sales amount elasticity were estimated as -0.8476 and 1.0144 , respectively. These indicate that industrial heat demand is inelastic to heat price and is elastic to the sales amount of heat. The value for price elasticity implies that it is difficult to adjust the demand for industrial heat instantly if there is fluctuation in the price of the industrial heat, because the industrial heat is an essential commodity for the manufacturing firms that use heat. On the other hand, the value for sales amount elasticity suggests that it can rapidly adjust the industrial heat demand in case the sales amount fluctuates.

Second, we need to look at the extent of the sales amount elasticity. The absolute value of the sales amount elasticity of demand is more than 1 and is estimated as a positive. This means that the industrial heat supply will continue to rise with the increase in the sales amount in the future. Therefore, the government will have to take appropriate measures against the expected increase in industrial heat demand. One of the most effective and useful demand management policies is price policy. How effective pricing is, however, depends on how sensitive individual manufacturing firms are to price. In other words, it depends on the size of price elasticity.

Third, the estimated price elasticity can be used for estimating the economic value or benefit of consuming heat. It is necessary to seek a stable supply of heat, an essential input factor, in line with the growth of the manufacturing sector. However, because investment in heat supply infrastructure is costly, the economic feasibility of the investment project should be considered. An economic feasibility analysis requires information about costs and benefits. Whereas cost information is relatively readily available, it is difficult to obtain information about benefits because it requires an academic approach. From the economic point of view, heat consumption benefits are defined as the upper area of the demand function for heat. The computation of the area requires numerical integration and requires a 
constrained assumption of the price at which demand is zero. On the other hand, Alexander et al. [30] suggested a relatively easy-to-use formula for computing the area as follows:

$$
\text { Economic benefits of consuming } Q_{0} \text { at price } P_{0}=P_{0} Q_{0}-\frac{P_{0} Q_{0}}{2 \mu}=P_{0} Q_{0}\left(1-\frac{1}{2 \mu}\right) \text {, }
$$

where $\mu$ is price elasticity and $P_{0} Q_{0}$ means the consumer expenditure.

Because $\mu=-0.8476,(1-1 / 2 \mu)$ in Equation (4) can be computed as 1.59. Therefore, it can be seen that the economic benefits of heat consumption in the South Korean manufacturing sector are 1.59 times higher than the heat price. This is quite interesting and useful information.

\section{Conclusions}

Estimating the heat demand function in the manufacturing sector is an important task, as heat consumption in the South Korean manufacturing sector is increasing. However, to the best of the authors' knowledge, this work has not been carried out so far. To do so, we need to collect micro data from manufacturing firms, which is not easy in terms of time and cost. Thus, this article attempted to estimate the heat demand function by collecting and analyzing cross-sectional data on 257 manufacturing firms. This analysis was successful in terms of the goodness-of-fit and statistical significance of the estimated demand function. In addition, this paper has some significance in research as well as policy aspects.

In terms of policy, this research derived quantitative information about the price elasticity and sales amount elasticity of industrial heat demand. These two elasticities represent essential information in forecasting heat demand, evaluating the economic value or benefits of the heat supply, and so on. More specifically, the price elasticity and the sales amount elasticity of demand were estimated to be -0.8476 and 1.0144 , respectively. The benefits of heat consumption were computed to be 1.59 times the price of heat. As there is currently no reliable quantitative information on heat supply benefits, the government evaluates the economic benefits of heat supply on the basis of cost information, such as the system's marginal price, when analyzing the economic feasibility of new heat supply public investment projects. However, because this study estimated the benefits of consuming heat for industrial use, it is necessary to utilize them.

From a research perspective, this study is significant in estimating the heat demand function for industrial use using cross-sectional data. The number of observations was 257. Although there have often been analyses using time-series data, there has been a lack of relevant research, because conducting a wide-ranging national survey of firms to obtain cross-sectional data requires considerable time and cost. In addition, instead of the LS estimation method, which is commonly applied in demand function estimation, the study used the LAD estimation method, which is known to be robust to the existence of outliers.

The main purpose of this paper was to estimate the demand function for industrial heat in the South Korean manufacturing sector. To do so, a nationwide survey of firms was implemented. In fact, the data gathered from the survey contain a lot of information. Therefore, a bottom-up analysis using all the information in the data can provide us with new insights about the industrial heat usage. It would be useful to carry out the analysis as a follow-up to this study.

The framework of this study needs to be expanded in two respects. First, if the panel data of manufacturing firms are constructed through years of survey and the demand function is estimated using that panel data, new insights can be obtained. In particular, because the dynamic analysis is possible using panel data, the application of models whose elasticity varies over time will be possible. This requires a multi-year follow-up survey of the same firms. Second, it is necessary to obtain a larger number of observations, divide the firms into several groups of sub-industries, and then estimate the demand function separately for each sub-industry. Because price elasticity and sales amount elasticity may vary from one sub-industry to another, a separate demand function will be required for each sub-industry. This would enable the establishment of policies differentiated by sub-industry. 
Author Contributions: All the authors made important contributions to this paper. H.-J.K. worked to draft and collect data, and created more than half of the manuscript; J.-S.B. carried out the literature review and wrote the remaining part of the manuscript; and S.-H.Y. was responsible for designing and applying the economic and statistical models needed to obtain the results.

Funding: This work was supported by the Korea Institute of Energy Technology Evaluation and Planning (KETEP) and the Ministry of Trade, Industry, \& Energy (MOTIE) of the Republic of Korea (No. 20184030202230).

Conflicts of Interest: The authors declare no conflict of interest.

\section{References}

1. International Energy Agency. Combined Heat and Power: Evaluating the Benefits of Greatest Global Investment; IEA Publications: Paris, France, 2008.

2. Agrell, P.J.; Bogetoft, P. Economic and environmental efficiency of district heating plants. Energy Policy 2005, 33, 1351-1362. [CrossRef]

3. Bianchi, M.; Branshini, L.; Pascale, A.D.; Peretto, A. Application of environmental performance of CHP systems with local and global approaches. Appl. Energy 2014, 130, 774-782. [CrossRef]

4. United States Department of Energy and United States Environmental Protection Agency. Combined Heat and Power: A Clean Energy Solution. 2012. Available online: http://www.doe.gov (accessed on 16 April 2019).

5. Afifi, S.N.; Hassan, M.G.; Zobaa, A.F. How market regulatory framework and policy affected the CHP development in meeting 2010 targets in the UK. Energy Sour. Part B Econ. Plan. Policy 2012, 7, 331-338. [CrossRef]

6. Kim, H.J.; Kim, H.H.; Yoo, S.H. The marginal value of heat in the Korean manufacturing industry. Sustainability 2018, 10, 1830. [CrossRef]

7. Korea Energy Agency. The Handbook of Integrated-Energy Business; Korea Energy Agency: Ulsan, Korea, 2017.

8. Behnaz, R.; Rosen, M.A. District heating and cooling: Review of technology and potential enhancements. Appl. Energy 2012, 93, 2-10.

9. Gebremedhin, A. Optimal utilisation of heat demand in district heating system-A case study. Renew. Sustain. Energy Rev. 2014, 30, 230-236. [CrossRef]

10. Geyer, P.; Delwati, M.; Buchholz, M.; Giampieri, A.; Smallbone, A.; Roskilly, A.P.; Buchholz, R.; Provost, M. Use cases with economics and simulation for thermo-chemical district networks. Sustainability 2018, 10, 599. [CrossRef]

11. Warr, B.S.; Ayres, R.U. Evidence of causality between the quantity and quality of energy consumption and economic growth. Energy 2010, 35, 1688-1693. [CrossRef]

12. Lim, K.M.; Lim, S.Y.; Yoo, S.H. Short- and long-run elasticities of electricity demand in the service sector in Korea. Energy Policy 2014, 67, 517-521. [CrossRef]

13. Chang, B.; Kang, S.J.; Jung, T.Y. Price and output elasticities of energy demand for industrial sectors in OECD countries. Sustainability 2019, 11, 1786. [CrossRef]

14. Du, N.; Shao, Q.; Hu, R. Price elasticity of production factors in Beijing's picking gardens. Sustainability 2019, 11, 2160. [CrossRef]

15. Lim, C. Estimating residential and industrial city gas demand function in the Republic of Korea-A Kalman filter application. Sustainability 2019, 11, 1363. [CrossRef]

16. Yoo, S.H.; Lee, J.S.; Kwak, S.J. Estimation of residential electricity demand function in Seoul by correction for sample selection bias. Energy Policy 2007, 35, 5702-5707. [CrossRef]

17. Dimitropoulos, J.; Hunt, L.C.; Judge, G. Estimating underlying energy demand trends using UK annual data. Appl. Econ. Lett. 2005, 12, 239-244. [CrossRef]

18. Adeyemi, O.I.; Hunt, L.C. Modelling OECD industrial energy demand: Asymmetric price responses and energy-saving technical change. Energy Econ. 2007, 29, 693-709. [CrossRef]

19. Adeyemi, O.I.; Hunt, L.C. Accounting for asymmetric price responses and underlying energy demand trends in OECD industrial energy demand. Energy Econ. 2014, 45, 435-444. [CrossRef]

20. Cialani, C.; Mortazavi, R. Household and industrial electricity demand in Europe. Energy Policy 2018, 122, 592-600. [CrossRef]

21. Sharimakin, A.; Glass, A.J.; Saal, D.S.; Glass, K. Dynamic multilevel modelling of industrial energy demand in Europe. Energy Econ. 2018, 74, 120-130. [CrossRef]

22. Chang, Y.; Kim, C.S.; Miller, J.I.; Park, J.Y.; Park, S. Time-varying long-run income and output elasticities of electricity demand with an application to Korea. Energy Econ. 2014, 46, 334-347. [CrossRef] 
23. Wang, N.; Mogi, G. Industrial and residential electricity demand dynamics in Japan: How did price and income elasticities evolve from 1989 to 2014? Energy Policy 2017, 106, 233-243. [CrossRef]

24. Filippini, M.; Pachauri, S. Elasticities of electricity demand in urban Indian households. Energy Policy 2004, 32, 429-436. [CrossRef]

25. Krishnamurthy, C.K.B.; Kriström, B. A cross-country analysis of residential electricity demand in 11 OECD-countries. Resour. Energy Econ. 2015, 39, 68-88. [CrossRef]

26. Koenker, R.W.; Bassett, G.W. Regression quantiles. Econometrica 1978, 46, 33-50. [CrossRef]

27. Bassett, G.; Koenker, R. Asymptotic theory of least absolute error regression. J. Am. Stat. Assoc. 1978, 73, 618-622. [CrossRef]

28. Espey, M.; Espey, J.; Shaw, W.D. Price elasticity of residential demand for water: A meta-analysis. Water Resour. Res. 1997, 33, 1369-1374. [CrossRef]

29. Yoo, S.H.; Lim, H.J.; Kwak, S.J. Estimating the residential demand function for natural gas in Seoul with correction for sample selection bias. Appl. Energy 2009, 86, 460-465. [CrossRef]

30. Alexander, D.L.; Kern, W.; Neil, J. Valuing the consumption benefits from professional sports franchises. J. Urban Econ. 2000, 48, 321-337. [CrossRef]

(C) 2019 by the authors. Licensee MDPI, Basel, Switzerland. This article is an open access article distributed under the terms and conditions of the Creative Commons Attribution (CC BY) license (http://creativecommons.org/licenses/by/4.0/). 